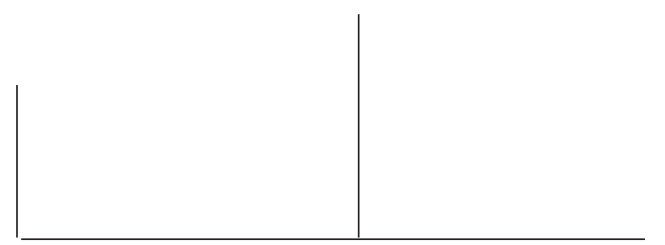

Rev. Latinoam. Psicopat. Fund., VII, 4, 44-58

\title{
Corpo e destrutividade: a construção de um limite
}

\author{
Isabel Castello Branco
}

\begin{abstract}
A concepção de André Green sobre os estados-limite, circunscrita pelos conceitos de destrutividade, relação de objeto e trabalho do negativo, é o ponto de partida para a investigação dos aspectos clínicos e metapsicológicos que permeiam a condução do caso discutido neste trabalho, cuja especificidade é também contemplada por meio de algumas considerações de Bion sobre a experiência analítica constituída nesses casos.
\end{abstract}

Palavras-chave: Destrutividade, narcisismo, estado-limite, afeto, objeto primário 


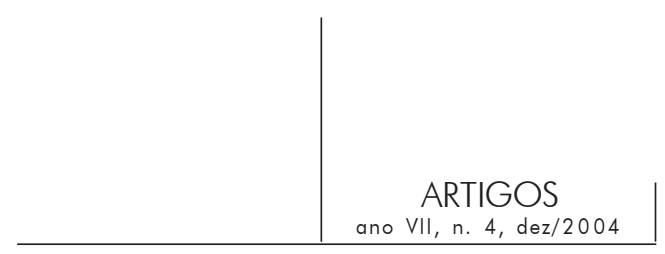

O psiquismo é a relação entre dois corpos, um dos quais está ausente

Green, 1998, p. 423

A partir das investigações de André Green e W. Bion sobre o que se convencionou designar como "estados-limite" ou borderline, pretende-se discutir um caso clínico cujo esboço apresento a seguir. Antes de tudo, interessa retomar algumas das observações que norteiam o pensamento de Green (2002, p. 465-86) ao mapear as relações entre histeria e estados-limite, para assinalar o fio condutor de seu trabalho no que diz respeito à questão referente à possibilidade destes últimos serem o indício de "um certo Zeitgeist" operando na determinação da psicopatologia contemporânea. Análise respaldada pela consideração da presença significativa desse tipo de quadro na clínica psicanalítica, pois, do seu ponto de vista, o que inicialmente parecia constituir uma parcela mínima dos pacientes, consiste, hoje, no "núcleo da população analítica". Nesse sentido, assim como outrora um certo "espírito do tempo" teria marcado a eclosão e o desenvolvimento da histeria - delimitando não só seu campo privilegiado de emergência, como também as formas de saber que dela se ocuparam -, a grande ocorrência desses quadros seria o indício de um movimento que exige compreensão.

Orientado por esse tipo de indagação, ele se dirige aos campos definidos pelos conceitos de histeria e estados-limite. Sua avaliação do desenvolvimento da literatura psicanalítica sobre o assunto aponta, com base no caráter proteiforme de ambas entidades, para o problema oriundo da insistência em definir esses quadros clínicos a partir de manifestações sintomáticas e para a necessidade de formular um quadro conceitual que procure explicar o polimorfismo das manifestações e os movimentos estruturais que os norteiam. Nessa perspectiva, importa retomar e pôr em questão o conceito de limite, "estendendo seu campo de ação tanto para a relação entre o ego e o objeto, como entre as diversas instâncias do aparelho psíquico" (ibid., p. 467). De um ponto de vista estrutural, seria possível também conceber o conceito de limite como constitutivo das diversas entidades. 


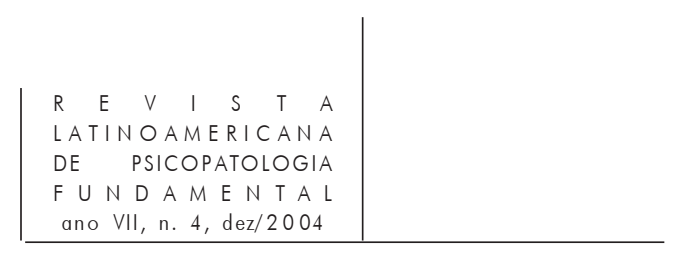

Portanto, a abordagem da "intersecção" entre histeria e estados-limite, tematizada a partir da comparação de um certo número de pontos através dos quais emergem sua delimitação e articulação, configura a busca da definição de um quadro conceitual que permita considerar e explicar a especificidade de ambas. Contudo, do esforço de síntese empreendido por Green, sublinho apenas o campo de discussão por ele circunscrito e os elementos mais imediatamente relacionados ao caso clínico em questão. Com esse objetivo, são retomadas algumas das considerações relativas ao conflito essencial às duas categorias. Assim sendo, no que concerne à histeria, salienta-se o fato de esta pertencer ao espaço delimitado pela neurose e se distinguir pela problemática das relações entre amor e sexualidade, na qual predominam questões relativas ao desejo, escolha objetal e identificações; quadro no qual adquire grande relevância a vida fantasmática e emocional, a relação com o corpo e a sensibilidade depressiva.

Quanto aos casos-limite, eles se caracterizariam pela ausência de uma organização neurótica e por formas de conflitos nas quais a problemática relativa ao amor, não necessariamente vinculada à sexualidade, desempenha um papel secundário em comparação com aspectos como a destrutividade, o masoquismo e o narcisismo. A tendência, presente na histeria, à fragmentação e ao despedaçamento do ego revela-se de maneira mais acentuada nos casos-limite, na propensão à despersonalização e no modo como o sujeito é afetado pelos sentimentos de perseguição e pela depressão, conduzindo a regressões significativas relacionadas aos fenômenos de dependência. Quadro marcado fundamentalmente por manifestações que permitem reconhecer a "fragilidade das fronteiras do ego". Ora, se na neurose destaca-se o papel da angústia de castração associada à angústia de penetração, os casos-limite são determinados por formas de angústia correspondentes ao âmbito do ego, relacionadas ao "temor de desmoronamento ou de invasão por um objeto hostil e agressivo", tais como a "angústia de separação" ou "angústia de intrusão", nas quais se evidencia o "medo da catástrofe" que pode levar a condutas projetivas, com predominância de atuações agressivas, situando a destrutividade no núcleo da problemática própria a esse quadro.

Apesar da referência um tanto esquemática aos problemas levantados por Green, essa breve introdução permite situar o quadro no qual se inscreve a reflexão sobre o caso clínico e, a partir de tal consideração, a função que nele desempenha a continência. Nesse sentido, investigar-se-ão elementos como a destrutividade, a relação com o corpo e a natureza do vínculo com o objeto primário, mas também o modo como esse tipo de quadro de certa maneira "situa" o analista. Assim, a partir da apresentação de um certo recorte da análise, delineiase a discussão dos aspectos clínicos e metapsicológicos distinguidos no trabalho analítico. 


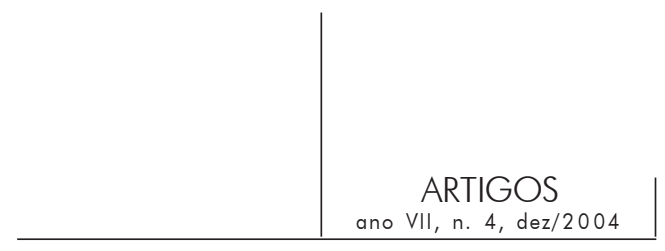

Apresentação do caso clínico ${ }^{1}$

As entrevistas iniciais, bem como a realizada com os pais da paciente, configuram uma espécie de "síntese" do material submetido à análise, do qual destaco algumas impressões. Trata-se de uma jovem ${ }^{2}$ que expressa, quase imediatamente e com nitidez, o campo no qual se articula grande parte de suas dificuldades. Desde a primeira entrevista se dirige a mim, tanto verbal quanto corporalmente, com muita intensidade; gesticula em demasia e se movimenta como se necessitasse de uma certa continência. Algumas das suas atitudes nessa ocasião são emblemáticas. Assim, por exemplo, poucos minutos depois de entrar no consultório, pergunta se pode tirar os sapatos, mas sem aguardar qualquer resposta, põe os pés na poltrona, fala e gesticula compulsivamente como se precisasse evitar minha presença. No entanto, depois dessa vigorosa atividade, salta da poltrona, senta no chão ao lado da minha e permanece encostada em mim até o final da entrevista, proximidade que parece de fato tranqüilizá-la. Durante essa primeira conversa, expõe com relativa facilidade, embora de maneira um tanto desordenada, os motivos que a levaram a procurar análise. Diz não saber o que aconteceu, mas passou a se vestir e se comportar como uma "maluca"; sempre esteve entre os melhores alunos do colégio, mas, nesse ano, foi reprovada em quase todas as disciplinas; trocou a sala de aula pelo bar e não consegue entender o porquê de não suportar mais assistir às aulas; está apaixonada (e se deixa humilhar) por um rapaz que a rejeita com muita clareza, quando estava acostumada a ter "os homens aos seus pés"; por fim, não tem a menor idéia do que provocou tudo isso, mas sabe precisar de ajuda.

Dois dias depois, ela chega ao consultório com vários ferimentos e bastante transtornada. Sentada no divã como se quisesse ficar ainda mais próxima do que na primeira entrevista, conta que na noite anterior, em meio a uma intensa discussão familiar, seu irmão a espancou e ela foi levada para o hospital. Ainda muito confusa, repete insistentemente que não conseguia entender o que tinha ocorrido, pois nunca tinham brigado dessa maneira. Supunha que os gritos de sua mãe, chamando-a de vadia, provocaram um "surto na família".

Pouco tempo depois, faço uma entrevista com os pais da paciente. Eles queriam conversar sobre os honorários, mas praticamente somente a mãe falou.

1. Agradeço a Flávio Carvalho Ferraz, e também a Mario Fuks e Silvia Alonso, pelo trabalho de supervisão deste caso.

2. Alguns dados foram propositalmente alterados para proteger a paciente da possibilidade de ser identificada. 


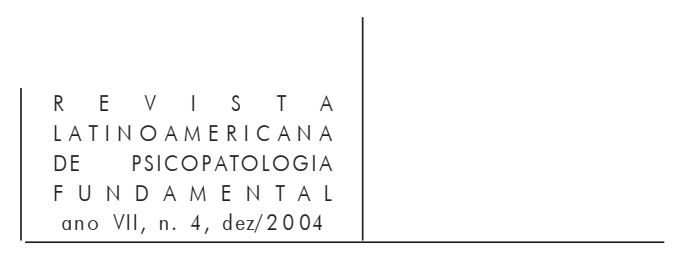

Sempre em um tom acusatório e exaltado, enumera sucessivos exemplos acerca do caráter maligno inato da filha, culpando-a pela sua "depressão". A mãe da paciente julga ter uma "depressão profunda" provocada pelo abandono do marido e da filha, com quem sonhou ter a mesma relação vivida com sua mãe (a avó de minha paciente). Até se casar (aos trinta e cinco anos de idade), após uma tentativa de suicídio ao saber que estava grávida, elas dormiam juntas e esse era o projeto a ser realizado com a filha. Sobre os seus tratamentos psiquiátricos, sugere que os médicos sempre foram incompetentes para diagnosticá-la. Segundo minha paciente, as tentativas de suicídio são relativamente freqüentes; sua mãe costuma cortar os pulsos e partes do corpo com cacos de vidro e, por vezes, simula engoli-los. No início da adolescência, depois de uma discussão com a mãe, durante a qual esta enfia um cesto de lixo em sua cabeça, é minha paciente quem ingere uma dose grande de remédios e bebida com a mesma finalidade.

O período inicial da análise é essencialmente marcado pela construção da possibilidade da paciente representar a relação com a mãe. A manifesta necessidade de afastamento não faz mais do que mantê-la num jogo especular; seus atos assemelham-se a uma espécie de "tentativa de fuga", constantemente reiterada, expressa num movimento autodestrutivo cuja correspondência com os atos da mãe passa a ser cada vez mais evidente. Nesse sentido, algumas "passagens ao ato" são exemplares. A primeira delas se traduz na "decisão" da paciente de corresponder à "imagem" que os pais tinham dela: frente aos constantes escândalos da mãe, nos quais esta se refere a ela como uma puta, escolhe corroborar tal designação, fazendo da promiscuidade um jogo. E, mesmo sabendo dos riscos, não manifesta preocupação quanto a isso. Seu critério é a beleza física, quer "experimentar" o maior número possível de homens e mulheres, viver todas as fantasias que lhe pareçam estimulantes. Tarefa à qual se dedica com o empenho de uma "pesquisadora de seres humanos". As brigas com a mãe são cada vez mais intensas e os castigos se multiplicam. Outras duas "atuações" são também significativas nesse período: dirigindo embriagada, ela bate o carro logo após sua mãe ter feito o mesmo e, depois de mais uma das "tentativas de suicídio" de sua mãe, abandona praticamente todas as suas atividades (inclusive a análise). Sua mãe corta os pulsos durante uma discussão com a avó e ela, depois de "muito calmamente" chamar o pai e limpar o sangue da escada, assiste à televisão e "se desliga do mundo".

A interpretação dessa repetição, construída durante esse momento da análise, permite começar a conectar seus movimentos autodestrutivos aos atos da mãe e aos seus sentimentos em relação a esta. Trata-se de um "vínculo" expresso nos atos intimamente ligados aos lugares a ela designados nas freqüentes discussões com a mãe, durante as quais esta se refere a ela como "porca, puta e louca"; bem como na reiteração dos próprios atos da mãe (bater o carro e tentar se matar). 


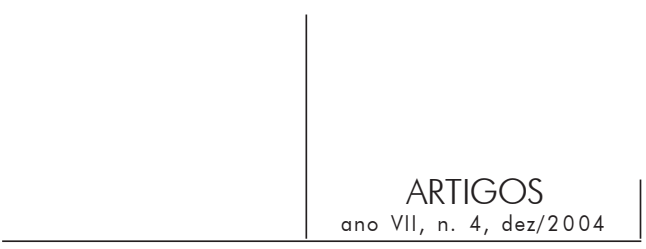

De uma tal forma que a recusa da demanda materna implica a aceitação dos "outros lugares" que lhe foram indicados: não dorme na mesma cama, mas segue rigorosamente o "roteiro" estabelecido e mantém-se totalmente presa ao "corpo materno". À percepção da natureza desse vínculo articula-se a possibilidade de verbalizar o ódio e o medo que acompanham esse contato; diz odiar que a mãe a toque, odiar seus carinhos, odiar quando ela a beija na boca, um ódio que a leva a sentir vontade de matá-la e, ao mesmo tempo, sentir-se culpada pela intensidade desses sentimentos. No entanto, além do ódio e do medo, depara-se também com a necessidade de uma relação que possa ser vivida de outra maneira; sensação experimentada como indício de fragilidade, à qual contrapõe orgulhosa sua tolerância à dor física ao fazer tatuagens e colocar piercing (sempre sem qualquer tipo de anestesia) em várias partes do corpo. Todo esse intenso movimento produz certas mudanças no modo de perceber a mãe; começa a referir-se não só ao ódio, mas também à solidão encontrada no seu rosto e à culpa por deixá-la sozinha. Sentimentos que lhe provocam uma "espécie de confusão".

Nesse período os pais se separam e ela interrompe a análise com a justificativa de precisar, com urgência, "sentir algo no corpo". Entretanto, comunicar-me o desejo de parar a análise foi extremamente difícil, seu progressivo afastamento se estende por quase dois meses. Somente a partir da formulação de uma curiosa saudação, pôde finalmente encontrar um "lugar" que lhe permitisse falar sobre o assunto. Assim, ao iniciar mais um dos inúmeros recados deixados na secretária eletrônica avisando que não viria novamente à sessão, se autodesigna como "minha paciente virtual" e faz a primeira tentativa de voltar ao consultório, mas chega atrasada e prefere deixar suas dificuldades por escrito na sala de espera. Tanto a carta quanto os atos que a precederam expressam com nitidez sua necessidade de interromper a análise e a angústia na qual se encontra imersa.

Sem dúvida, tal movimento é determinado pela natureza da relação de transferência que se estabelecera. Contudo, a intensidade da angústia que a acompanha exigia outro tipo de consideração. Um mês para conseguir ir ao consultório e escrever sobre o desejo de interromper a análise apresentavam-se como indícios significativos da necessidade de cuidado com o tipo de intervenção a ser feita. Impressão que se confirma na resposta à proposta de conversarmos pessoalmente sobre o sentido da palavra virtual e o desejo de interromper a análise, restrita quase exclusivamente à sua peculiar gargalhada nervosa e aos infalíveis pedidos de desculpa. Dificuldade da qual infiro não só a importância de tranquiilizá-la quanto à possibilidade do encontro (e separação), mas de assegurála que eu sabia tratar-se de questões mais complexas do que "não gostar de mim" ou "ser mal-agradecida", como escreveu temer que eu sentisse. 


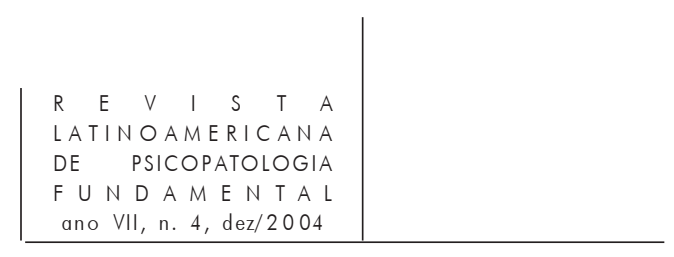

Ela consegue ir ao consultório e durante a sessão reafirma-se a impressão de que seria fundamental não opor qualquer restrição à sua necessidade de parar a análise. Novamente, mais do que à interpretação da transferência ou da resistência, ative-me à angústia que acompanhava não só o modo de ela se dirigir a mim, extremamente assustado, mas às "atuações": marcara ostensivamente o corpo com piercing e tatuagens (sempre sem anestesia). Como ela tinha deixado claro, não havia espaço para um outro; senão sob o impacto de uma vivência profundamente ameaçadora. Nada disso era virtual, a angústia parecia precisar incrustar-se no corpo. Perguntava-me quem (ou o que) eu me tornara para ela nesse espetáculo pretensamente virtual. Interpretei a interrupção como um momento da análise. Ela precisava sentir que podia se separar. Algo se atualizara na análise com a separação dos pais, mas nenhuma pergunta encontrara espaço; só lhe foi possível falar sob a forma da ausência e de uma "atuação" violenta sobre o corpo, uma espécie de mapa da impotência e talvez do desespero e do gozo. Seja como for, a emergência de qualquer questão e a própria elaboração da necessidade de interromper a análise pareciam depender da vivência de separação encenada na análise e ser continente deste movimento constituía a interpretação possível. Por outro lado, a expressão utilizada para definir a si mesma ao pretender parar a análise, ou seja, "paciente virtual", parecia dizer mais do que tinha condições para formular nessa ocasião, pois virtual designa não só a simulação de algo criada por meios eletrônicos, o que existe apenas em potência e não como realidade; mas, simultaneamente, por extensão de sentido, aquilo que poderá vir a ser, existir, acontecer.

De fato, alguns meses depois, ela retoma a análise. Em um estado depressivo, queixa-se de ter perdido o interesse pela vida e pelas pessoas, de estar com medo de ficar parecida com a mãe. Sente-se confusa pela falta do sentimento de alegria e alívio que esperava acompanhar sua ausência. No entanto, a simples perspectiva de visitá-la a aterroriza, quer manter-se longe e esquecer. Vinculada à "necessidade de esquecer", encontra-se a repetição de certos atos que permite vislumbrar um modo peculiar de "lembrar". Trata-se de uma comunicação sutil. A transferência, até então expressa de maneira preponderante sob a forma do sentimento de gratidão, parece adquirir de modo progressivo um caráter de controle e hostilidade, manifesto na exigência do silêncio sobre o passado e na identificação a determinados "lugares". Circunstância em que são exemplares atitudes como: espalhar sapatos, bolsa, agenda e telefone pelo chão do consultório, de maneira a deixá-lo temporariamente em desordem e literalmente sujo depois de sua saída; atender ao telefone celular durante a sessão, interrupção precedida sempre por um negligente "perấ"; um relato exibicionista, marcado por uma ironia sarcástica, tanto do modo como "escolhe seus homens" como dos lugares do corpo em que colocou piercing. "Seu último homem", como faz questão de no- 


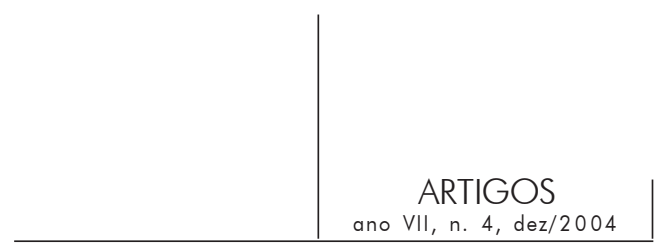

mear, foi escolhido numa casa noturna: ela olha pra ele, espera o momento propício e o convida para irem juntos ao banheiro. Depois de afirmar insistentemente que foi excitante ter relações sexuais no banheiro e o quanto lhe dá prazer abordar e convidar um homem dessa maneira, diz ter feito isso por carência, por não suportar estar apaixonada e a ansiedade e o medo de rejeição que a assombram.

A vivência dessa defesa diante da angústia provocada por tais sentimentos não a impede de "atuar" e, tampouco, de encenar (também no consultório) os papéis da "porca" e da "puta". A projeção desses conteúdos - atualizada de forma não só a impor sua existência, mas a violência e a impotência às quais já se encontrou submetida -, expressa a necessidade de uma experiência que lhe permita recordar da louca e de cuja continência decorra a possibilidade de pensá-los. Nesse movimento, através de uma interessante construção, pôde passar da afirmação acerca da loucura de todas as mulheres para a questão do que é ser uma mulher louca e de sua identidade nessa constelação. Diferenciar-se implicou a experiência de começar, verdadeiramente, a lembrar. Nesse sentido, e apenas como um exemplo do andamento dessa composição, pela primeira vez lhe ocorre a idéia de que todos os seus "acidentes" estiveram relacionados a "ordens" da mãe, mais ou menos cronologicamente encadeadas por meio de acontecimentos que envolveram ameaças à vida. Por fim, suponho que a exigência de "esquecer", com a qual retorna à análise, evoca o espectro da defesa frente à possibilidade de pensar na mãe e no medo de ser como ela; em relação a isso a violência sobre si mesma foi seu modo de triunfar. Esse ato talvez concentre impotência, desespero e gozo, mas exprime também, através desse recordar cuja especificidade parece inscrever-se no corpo e nas atuações, a tentativa de construção de um limite.

\section{Comentário sobre o caso clínico}

Entre os aspectos mais significativos do caso, assinala-se o papel da articulação entre destrutividade e constituição narcísica - expresso na relação da paciente com a mãe e com seu próprio corpo -; articulação manifesta, por exemplo, no predomínio de defesas arcaicas diante das angústias de separação e intrusão. Essa articulação se dá a conhecer também nos contornos pouco nítidos nas relações entre ego e objeto, indícios de prejuízo na constituição da representação do eu e do objeto (definida a partir da relação com o objeto primário); perceptível nas "passagens ao ato" - mobilizadas por afetos como ódio, impotência e desespero - através das quais parece se configurar uma busca reiterada de "negativizar a presença da mãe"; processo impedido no momento de constituição do narcisismo justamente por um "excesso de presença”, ou melhor, 


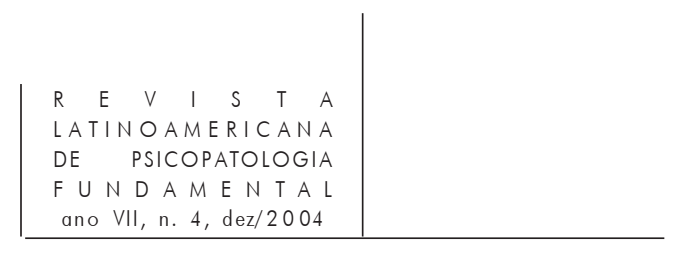

por uma presença materna vivida como intrusiva e possessiva. Ou seja, na falta de um "espaço interior" que permita à paciente se subtrair a esse excesso, parece realizar através de seu corpo uma espécie de "alucinação negativa permanente do pensamento"; de tal modo que em lugar de uma delimitação dos pensamentos se produz uma espécie de expulsão aflitiva destes sob a forma da destruição de si. As "atuações" testemunham esse movimento e a relação da paciente com o próprio corpo parece, acima de tudo, registrá-lo. Assim, marcar o corpo e ser capaz de triunfar sobre a dor é índice do tipo de vínculo vivido com a mãe, repetindo talvez até mesmo as marcas que esta deixa em seu corpo nas constantes tentativas de suicídio, mas sobretudo expressão dessa espécie de "alucinação negativa do pensamento".

Essa "ambivalência" inscreve-se no corpo e nos atos. As tentativas de suicídio, o mapeamento do corpo com piercing e tatuagens, como também a promiscuidade que caracteriza seu modo de se relacionar sexualmente com homens e mulheres, são movimentos que fazem pensar na hipótese de uma certa "erotização do sofrimento", como aspecto determinante nas diversas formas de destrutividade das quais se serve a paciente. De fato, o excesso de conotação sexual parece remeter à impossibilidade de separação em relação ao objeto primário, ou seja, é a natureza (e as consequiências) do "vínculo mortal" com a mãe que põe em andamento certas formas arcaicas de defesa em relação aos afetos, vividos como ameaças de desintegração do ego. Esse corpo inundado pela angústia não encontra outra saída além das atuações agressivas. Contudo, como assinala Green (1998, p. 441), a destrutividade liga-se necessariamente à libido erótica, mobilizando o que designa como "pulsionalização das defesas", ou seja, o "Eros das pulsões de vida", ao perpassar de maneira brutal as instâncias do ego, provoca reações de mesma intensidade e torna-se ameaçador da identidade do sujeito, incapacitando-o para uma outra relação de objeto e convertendo este último em fonte de desconfiança e perigo permanentes. Nesse caso, uma grande parte da destrutividade se fixa no funcionamento do ego, de modo a determinar condutas repetitivas e comportamentos de evasão; quadro ao qual tem-se a impressão de que na

... impossibilidade de exercer o mínimo domínio sobre os afetos transbordantes e desorganizadores, torna-se imperativo colocar a maior distância tanto diante das representações mais próximas quanto das mais afastadas, tornando-as, de fato, inacessíveis. Isso implica reduzir as possibilidades de dar um sentido que seja capaz de ligar pulsões e objetos. Resta a parte que cabe ao irrepresentável, freqüentemente a mais importante. (ibid., p. 442)

A temática da representação e do afeto, assim como a questão da discriminação entre ambos, situa-se no cerne do interesse de Green pelos "estados-limite" 


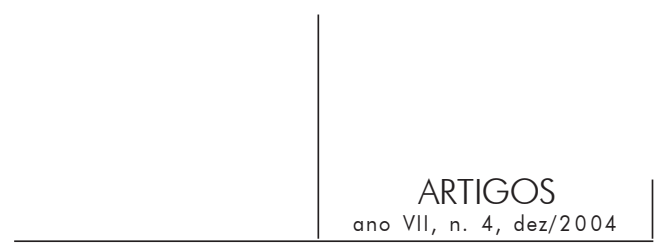

e implica um longo desenvolvimento teórico, no qual se destaca uma considerável reflexão sobre o que designou como "trabalho do negativo". O conceito de negativo começa a se delinear na obra de Green em meados da década de 1960 e encontra sua formulação final no texto de 1993, intitulado Le travail du négatif. Portanto, não se trata - evidentemente - de fazer uma síntese do longo percurso (e necessária complexidade) que recobre tal conceito, mas apenas de localizar o quadro mobilizado para pensar algumas das questões presentes neste caso, à medida que contempla um de seus traços mais relevantes, a saber, os limites da representação e a destrutividade. Com o propósito de introduzir tal discussão, refiro-me ao que considero um dos aspectos nucleares de sua reflexão acerca do conceito de "negativo". Assim sendo, esse conceito se define como o que se encontra nos limites da representação (como efeito do inconsciente e como destrutividade), espécie de conteúdo vazio ou irrepresentável relacionado com as pulsões, em particular com a pulsão de morte. Quanto ao "trabalho do negativo", ele transforma esses limites da representação em "continente", ou seja, em limites do próprio aparelho psíquico representativo.

O interesse de Green pelo negativo comporta uma certa configuração em sua obra desde 1966, no texto "L'inconscient", no qual se refere ao "momento negativo da pulsão". No entanto, a noção de negativo adquire valor expressivo a partir de 1967, com o trabalho sobre a neurose obsessiva, intitulado Métapsychologie de la névrose obsessionnelle, desenvolvido em torno da relação da pulsão de morte com o desinvestimento dos objetos nos mecanismos próprios a essa afecção. Mas embora permitam reconhecer a preocupação com a investigação dos "casos-limite", esses trabalhos inscrevem-se no registro da compreensão dos fenômenos próprios à neurose. Assim, a primeira formulação mais consistente no estudo dos estados-limite encontra-se no trabalho dedicado à investigação do "narcisismo negativo", ou "narcisismo de morte", e com a apresentação da teoria da "alucinação negativa" no livro de 1967, Le narcissisme primaire, structure ou état, seguido por uma série de artigos reunidos e publicados em 1983 sob o título de Narcissisme de vie, narcissisme de mort. Nesses trabalhos, opõe dois modelos do narcisismo em Freud: o "narcisismo primário", que visa o rebaixamento de todas as tensões a zero, evocando a pulsão de morte, e o "narcisismo secundário", que visa a conservação e a representação. O problema a ser enfrentado se refere ao modo como a pulsão de morte está ligada ao aparelho psíquico e à compreensão do dano causado em tal ligação como acesso ao tratamento dos casoslimite. Para Green, é a partir da ausência (realizada sobre uma certa presença) que se constitui no sujeito uma estrutura que conforma o psiquismo; fenômeno por ele descrito como "alucinação negativa do objeto primário" e cuja impossibilidade está na origem das patologias narcísicas mais graves. 


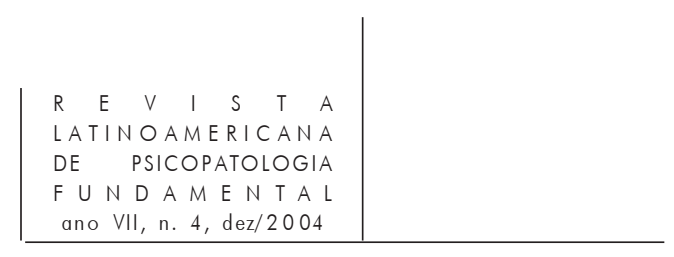

Dito de outra maneira, a questão subjacente a essa investigação refere-se à forma como o funcionamento pulsional distinguido nos casos-limite articula-se à relação com o objeto primário. Do ponto de vista de Green, a resposta a essa questão deve orientar um certo reparo à teoria freudiana das pulsões, que teria privilegiado a representação da ausência do objeto em detrimento das dificuldades da percepção em sua presença, elidindo o lugar do objeto no nível do "narcisismo primário". Tratar-se-ia, portanto, de evidenciar o papel determinante da "resposta psíquica" fornecida pelo objeto primário aos investimentos pulsionais que lhe são dirigidos e que não pode ser considerada como secundária, pois "uma introjeção se produz sobre o par investimento-resposta interna e externa, tornado totalidade indissociável" (Green, 1998, p. 442). Green descreve, a partir da consideração da especificidade dessa "totalidade indissociável", sua determinação nas estruturas não neuróticas. Conseqüentemente, é no interior da própria demanda dirigida ao objeto que a criança instala a mãe dentro de si, tornando-se necessário "incluí-la em seu psiquismo inconsciente, ligá-la aos vestígios das experiências anteriores, transformá-la e dar-lhe uma forma singular e pessoal" (ibid., p. 443); processo cuja impossibilidade dá origem às formas mais mutiladoras do trabalho do negativo, através das quais o que importa ao sujeito é o não reconhecimento de si. Em tal contexto, o recalque desempenha papel limitado em prol de mecanismos como a denegação, a cisão ou a recusa.

Portanto, o objeto intervém na gênese desses mecanismos e disso decorre que a separação em relação ao objeto primário somente se realiza na medida em que existam condições de possibilidade para um tal movimento. Ao longo do desenvolvimento dessa proposição, Green faz uma importante construção a partir da teoria freudiana, assim como dos trabalhos de Winnicott e Bion, cuja argumentação tem início com uma certa descrição dos quadros próprios aos estados-limite. Estes se caracterizariam não só pela ausência de "formações intermediárias", ou seja, pela falta de "produções psíquicas organizadas por processos primários que implicam um relativo trabalho de diferenciação entre afeto e representação" (ibid., p. 449), mas também por expressarem, além de modos de funcionamento psíquico pouco discriminativos, "estados de não-separação entre sujeito e objeto, de agarramento ao objeto, num modo de relação destrutivo e masoquista, marcado por uma sexualidade imperiosa, mal diferenciada e submetida a uma constante decepção, justamente em relação com uma perseguição que encontraria sua fonte no objeto primário" (ibid.). A explicação de um tal quadro reside na impossibilidade de constituição de uma "organização psíquica primária", condição para o desenvolvimento das relações intrapsíquicas e intersubjetivas, para a qual a relação com o objeto primário é determinante, pois "permite a instauração dos processos internos em sua relação com o inconsciente". Contudo, a inscrição dessas 


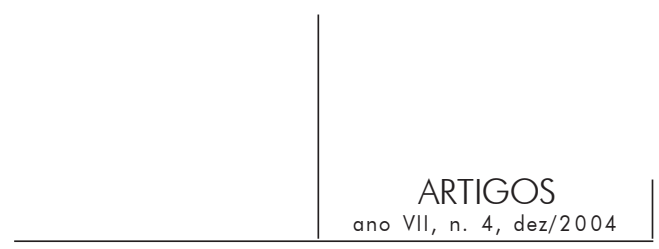

"formações intermediárias" no psiquismo depende - como assinalaram, cada um a seu modo, autores como Winnicott e Bion - "da constância e da manutenção do investimento materno que sobrevive a todos os acasos e transformações da relação, até mesmo dos aspectos desta que podem comportar importantes cargas destrutivas" (Green, 1998, p. 450). Em suma, como foi possível acompanhar, a concepção de Green sobre as estruturas não neuróticas envolve uma construção - aqui circunscrita sobretudo pelos conceitos de moção pulsional, relação de objeto e trabalho do negativo - a partir da qual emerge o papel determinante das questões relativas à natureza do vínculo com o objeto primário na gênese dessas estruturas, caracterizadas por um comprometimento no âmbito do afeto e da representação.

Ainda que a dimensão da articulação posta em andamento pela obra de Green exija uma exposição mais criteriosa, sua abordagem neste trabalho está em consonância com o propósito de delinear um comentário sobre as questões clínicas e metapsicológicas suscitadas durante o processo de análise do caso apresentado. Em tal contexto, a teoria assemelha-se a um modelo que pretende, antes de tudo, a compreensão e a instauração de um certo diálogo sobre o conjunto e a dinâmica dos elementos que nomeia. Nessa perspectiva insere-se a discussão relativa à fronteira entre estados-limite e histeria, sobretudo no que se refere ao conflito próprio às diferentes estruturas como critério de determinação dos quadros clínicos, do que decorre a consideração acerca daquele no qual se inscreve esse caso. Assim, destrutividade e narcisismo, bem como o campo articulado por ambos, são aspectos significativos na definição do quadro designado como "estado-limite" e se manifestam com suficiente nitidez nas diferentes formas de expressão do conflito presentes no tratamento dessa paciente. No que diz respeito a este último, são evidentes não só o aprisionamento ao objeto primário e às formas de relação com ele estabelecida, como também o vínculo dessas relações e do aprisionamento a uma espécie de "pulsionalização das defesas" revelada nas condutas repetitivas, nas quais a destrutividade se fixa ao funcionamento do ego, comprometendo a discriminação entre afeto e representação. Em síntese, desde a perspectiva das investigações de Green aqui delineadas, esses elementos encontram-se em estreita ressonância com o que a experiência analítica com esta paciente permitiu compreender.

Por fim, algumas breves observações relativas à especificidade da experiência analítica afiguram-se como necessárias. Antes de qualquer coisa, enquanto analistas nos envolvemos em uma experiência da qual a linguagem utilizada em nossos trabalhos parece por vezes fazer um mero registro descritivo; efeito provável da natureza dos processos próprios a essa linguagem que terminam por franquear os limites entre psicanálise e fenomenologia, elaborando um relato que tende a objetivar a pluralidade intrínseca à experiência constituída pelo par 


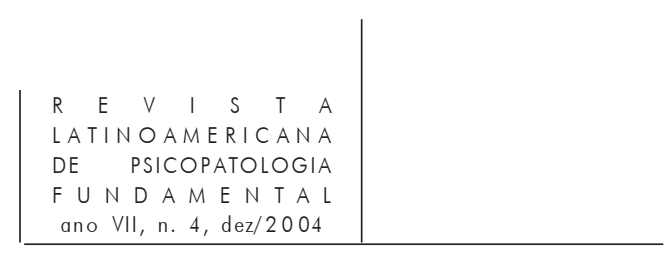

analítico. ${ }^{3}$ Entretanto, é também às voltas com esse tipo de dificuldade que o pensar se constitui. O fato é, escreve Green em um belo texto intitulado "A experiência e o pensamento na prática analítica", que "embora o significado do que acontece nesta experiência possa ser obscuro para nós, ainda somos capazes de sentir a experiência, de falar sobre ela, ainda que o significado do que está acontecendo possa nos escapar. O que podemos dizer é que a experiência é uma realização" (ibid., 2003, p. 1-2). Com esse termo assenta a especificidade desta em sua inerência à natureza histórica do homem, expressa no processo que se efetiva no trabalho desenvolvido entre analista e analisando, que não se reduz à recuperação ou mesmo à revivescência do passado, porque está essencialmente determinado "em fazer o presente e o existir no presente como ser histórico" (ibid., p. 12).

De qualquer forma, outra fundamental contribuição oferecida às considerações sobre a experiência e o pensamento na psicanálise, desenvolvida na teoria bioniana, se distingue como uma construção profícua que permite reconhecer o tipo de dificuldade que envolve o tratamento nos casos-limite. Antes de tudo, essas investigações de Bion têm como fio condutor a compreensão de fenômenos associados ao processo psicótico, na qual se destaca a conceituação acerca da personalidade psicótica que designa, grosso modo, um funcionamento mental essencialmente determinado por formas de ataque ao ego, ao pensamento e pela "identificação projetiva patológica". Na origem da predominância desse funcionamento mental sobre outros, ele situa a presença de uma mãe dotada de pouca (ou nenhuma) "capacidade de rêverie" e, por conseguinte, inábil para realizar a função de receber, conter e modificar as emoções projetadas pela criança; incapacidade que compromete o desenvolvimento da "parte não psicótica da personalidade". Nesses casos, caberia ao analista a função de conter, articular e transformar certos conteúdos, designada como "função continente", concebida "como uma espécie de sonhar interpessoal" (Caper, 2002, p. 189). Dito aqui de modo um tanto esquemático, caberia ao analista o papel de converter elementos beta (não significativos e não conectados entre si) em elementos alfa (significativos e passíveis de conexão uns com os outros), ou melhor, "receber conteúdos mentais que são impensáveis e impossíveis de vivenciar" e transformálos de forma que possam vir a ser pensados e vivenciados, processo ao fim do qual se dá a interpretação. Desse ponto de vista, portanto, a interpretação subordina-se, ou melhor, está determinada por um conjunto dinâmico de aspectos mobilizados na construção da teoria do pensamento, no qual a "função alfa" porta

3. André Green faz um interessante comentário sobre essa questão no texto "Objeto(s) e sujeito" (2003, p. 13). 


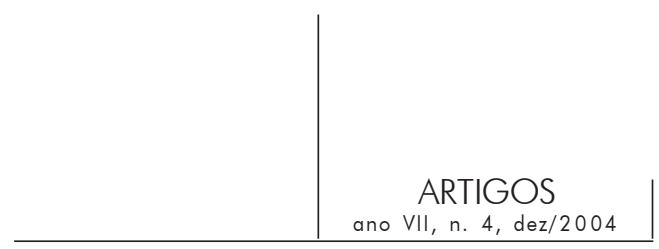

a possibilidade de transformação de certos conteúdos e, enquanto tal, relacionase ao desenvolvimento da capacidade de pensar e aprender com a experiência emocional.

Apesar da complexidade própria à construção da teoria bioniana e de sua importância na compreensão da especificidade dos fenômenos envolvidos nos estados-limite, sublinho apenas uma das questões dela constitutiva, ou seja, o tipo de intervenção exigida em um quadro no qual certos conteúdos se apresentam como "impensáveis" e cuja determinação não reside na referência a lembranças irrecuperáveis, quer em função de afetos dolorosos ou ainda da intensidade destes. No caso clínico apresentado essa questão se coloca desde o início do tratamento e, com base nesse tipo de consideração, a condução da análise norteia-se pela constituição de uma experiência passível de permitir à paciente a vivência, anteriormente prejudicada, de lidar com conteúdos extremamente desorganizadores e ameaçadores do ego. Em outros termos, suponho que no caso em discussão, a busca inconsciente do corpo materno e sobretudo de diferenciação não remete ao recalcado, mas ao que Bion designa como impensável e Green como irrepresentável e - em um tal quadro - é no sentido acima referido de "continente" que a interpretação deve se colocar; ou melhor, na medida em que se orienta pela possibilidade de "transformação", a função de continente dos movimentos autodestrutivos e da angústia deve conduzir a análise. Esse tipo de "transformação" dá-se a conhecer com alguma nitidez no modo como a paciente passa a operar com o próprio corpo no momento da separação dos pais, convertendo-o numa espécie de "barreira de contato", por meio da qual parece procurar construir uma certa representação da diferença e simbolizar uma distinção entre "eu e não-eu"; processo que envolve não só a alteração dos movimentos com os quais iniciou a análise, mas também a possibilidade de começar, verdadeiramente, a lembrar da "louca", dos seus atos, da sua violência, do medo que isso lhe provoca e, acima de tudo, vivenciar e elaborar o terror de se sentir parecida com ela.

\section{Referências}

Bion, W. R. O aprender com a experiência. Rio de Janeiro: Zahar, 1966.

CAPER, R. Tendo mente própria: uma visão kleiniana do self e do objeto. Rio de Janeiro: Imago, 2002.

Green, A. Le travail du négatif. Paris: Minuit, 1993.

Sobre a discriminação e a indiscriminação afeto-representação. Revista

Brasileira de Psicanálise. São Paulo: ABP, v. XXXII, n. 3, p. 407-56, 1998. 


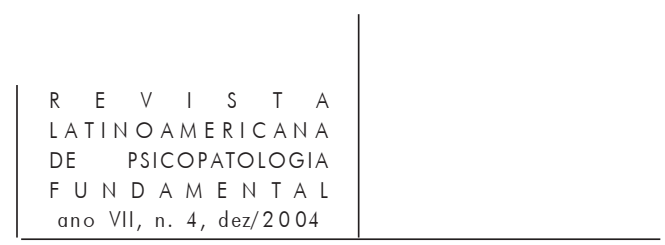

Histeria e estados-limite: quiasma. Novas perspectivas. Revista Brasileira de Psicanálise. São Paulo: ABP. v. XXXVI, n. 3, p. 465-86, 2002.

A experiência e o pensamento na prática analítica. In: JAN ABRAM (org.) André Green e a Fundação Squiggle. São Paulo: Roca, p. 1-12, 2003.

Objeto(s) e sujeito. In: JAN ABRAm (org.). André Green e a Fundação Squiggle. São Paulo: Roca, p. 13-29, 2003.

\section{Resumos}

La concepción de André Green acerca de los estados-límite, circunscrita por los conceptos de destructividad, relación de objeto y trabajo del negativo, es el punto de partida para la investigación de los aspectos clínicos metasicológicos contenidos en la conducción del caso discutido en este trabajo, cuya especificidad también es contemplada por intermedio de algunas consideraciones de Bion acerca de la experiencia analítica constituida en estos casos.

Palabras claves: Destructividad, narcisismo, estado-límite, afecto, objeto primario

La conception d'André Green concernant les états limites, circonscrite par les concepts de destructivité, de relation d'objet et de travail du négatif, est le point de départ d'une investigation des aspects cliniques et métapsychologiques qui traversent la conduite du travail clinique concernant le cas discuté dans cet ouvrage, dont la spécificité est également envisagée a partir de certaines considérations de Bion vis-àvis de l'expérience analytique constituée dans ces cas.

Mots clés: Destructivité, narcissisme, état limite, affection, objet primaire

André Green's concept of borderline states bound by the concepts of destructiveness, object relations and negative work is the starting point for investigating clinical and meta-psychological aspects involved in the case discussed in this article. This subject is also treated in the light of Bion's considerations on the analytic experience that occurs in these cases.

Key words: Destructiveness, narcissism, borderline state, affection, primary object

Versão inicial recebida em janeiro de 2004

Aprovado para publicação em junho de 2004 